\title{
Analisis Perbandingan Dosis Keluaran Berkas Radiasi Pesawat Co-60 Merek Theratron Phoenix Dari Perubahan Nilai Panjang Dan Lebar Persegi Panjang Pada Luas Lapangan Yang Sama
}

\author{
Alya Nabilla ${ }^{1}$, Dian Milvita ${ }^{2}$, Mursiyatun ${ }^{3}$ \\ 1,2 Program Studi S1 Fisika, Fakultas MIPA, Universitas Andalas, \\ Limau Manis, Kec. Pauh, Kota Padang Sumatra Barat, 25175 \\ ${ }^{3}$ Instalasi Radiologi dan Kedokteran Nuklir Rumah Sakit Dr. M.Djamil Padang, Jl. Perintis \\ Kemerdekaan, Sawahan Timur, Kec. Padang Timur, Kota Padang, Sumatra Barat, 25171 \\ Email : deeralyanabi@gmail.com
}

\begin{abstract}
Research has been carried out on the comparative analysis of the radiation dose of the Co-60 with the theratron phoenix by two stages, first to analyze the output dose according to the recommendations of the TRS 398 IAEA protocol with a field of $10 \mathrm{~cm} \times 10 \mathrm{~cm}$, a depth of $5 \mathrm{~cm}$ and SSD $80 . \mathrm{cm}$, which aims to calculate the output factor, the second is to analyze the ratio of the output dose of changes in the value of length and width of the rectangle on the same field with five variations of the field, the results are compared according to the quality assurance by the AAPM TG 40. The results showed that the error value in the $10 \mathrm{~cm} \times 10 \mathrm{~cm}$, the error value was $0.05 \%, 5 \mathrm{~cm} \times 6 \mathrm{~cm}$, the error value for each change value was $0.426 \%, 0,106 \%, 0.530 \% .5 \mathrm{~cm} \times 8 \mathrm{~cm}: 0.211 \%, 0.210 \%$, and $0.419 \%$. $5 \mathrm{~cm} \times 13 \mathrm{~cm}: 0.207 \%, 0.311 \%, 0.104 \% .6 \mathrm{~cm} \times 12 \mathrm{~cm}: 0.206 \% .6 \mathrm{~cm} \times 19 \mathrm{~cm}: 0.610 \%, 0.713 \%$, $0.102 \%$. The value is still within the tolerance limit of the Co-60 AAPM TG 40 quality assurance protocol $2 \%$.
\end{abstract}

Keywords: output dose, Co-60, TRS 398 IAEA, AAPM TG 40

\begin{abstract}
Abstrak: Telah dilakukan penelitian tentang analisis perbandingan dosis keluaran berkas radiasi pesawat Co-60 merek theratron phoenix, penelitian dilakukan dalam dua tahap, pertama menganalisi s dosis keluaran sesuai dengan rekomendasi protokol TRS 398 IAEA dengan luas lapangan $10 \mathrm{~cm} \times 10$ $\mathrm{cm}$, kedalaman $5 \mathrm{~cm}$ dan SSD $80 \mathrm{~cm}$, yang bertujuan untuk menghitung faktor keluaran yang akan digunakan pada tahap selanjutnya, kedua menganalisis perbandingan dosis keluaran dari perubahan nilai panjang dan lebar persegi panjang pada luas lapangan yang sama dengan lima variasi luas lapangan, hasilnya dibandingkan sesuai dengan quality assurance yang dikeluarkan protokol AAPM TG 40 untuk Co-60. Hasil penelitian menunjukkan nilai error atau deviasi pada luas lapangan $10 \mathrm{~cm} \times 10 \mathrm{~cm}$ nilai error sebesar $0,05 \%$, luas lapangan $5 \mathrm{~cm} \times 6 \mathrm{~cm}$ nilai error terhadap masing-masing nilai perubahan sebesar $0,426 \%, 0,106 \%, 0,530 \%$. Luas lapangan $5 \mathrm{~cm}$ x $8 \mathrm{~cm}$ nilai error sebesar $0,211 \%, 0,210 \%$, dan $0,419 \%$. Luas lapangan $5 \mathrm{~cm} \times 13 \mathrm{~cm}$ nilai error sebesar $0,207 \%, 0,311 \%, 0,104 \%$. Luas lapangan $6 \mathrm{~cm}$ x $12 \mathrm{~cm}$ nilai error sebesar $0,206 \%$. Luas lapangan $6 \mathrm{~cm}$ x $19 \mathrm{~cm}$ nilai error sebesar $0,610 \%, 0,713 \%$, $0,102 \%$. Nilai masih berada dalam batas toleransi quality assurance Co-60 protokol AAPM TG 40 yaitu $2 \%$.
\end{abstract}

Kata kunci: dosis keluaran, Co-60, TRS 398 IAEA, AAPM TG 40.

\section{PENDAhULUAN}

Radioterapi adalah salah satu metode pengobatan kanker yang memberikan harapan hidup lebih lama untuk penderita kanker. Berdasarkan pada jarak antara sumber radiasi terhadap target radiasi, maka radioterapi dapat dibedakan menjadi dua kelompok yaitu brakiterapi (radioterapi internal) dan teleterapi (radioterapi eksternal). Ketika kanker harus disinari dengan 
radiasi, sel-sel kanker harus diusahakan menerima dosis radiasi sesuai dengan besar dosis radiasi yang telah ditentukan dan sel-sel normal di sekitarnya menerima dosis serendah mungkin. Sebelum dilakukan penyinaran diperlukan dua macam informasi guna menghitung besarnya dosis radiasi yang akan diberikan pada pasien. Pertama adalah data yang berkaitan dengan pasien itu sendiri, letak dan volume kanker harus sudah diketahui secara pasti dari hasil diagnosis sebelumnya. Kedua adalah data yang berkaitan dengan berkas radiasi, dosis acuan, lapangan radiasi dan distribusi dosis radiasi.

Penelitian Baba dkk (2013), melakukan perhitungan ketepatan dosimetri dari pesawat terapi Co-60 menggunakan analisis dari perbandingan dosis radiasi keluaran yang diterima berdasarkan protokol TRS 398 IAEA dengan perhitungan yang diperoleh dari proses peluruhan Co-60 hasilnya, dosis radiasi keluaran yang diterima pasien dibandingkan dengan perhitungan proses peluruhan Co-60 dosis menunjukkan penyimpangan yang masih dalam batas toleransi yaitu $2 \%$.

Penelitian lain tentang perhitungan ketepatan dosimetri dari pesawat Co-60 yaitu Memon dkk (2017), melakukan ketepatan antara dosis radiasi keluaran yang diterima sesuai protokol TRS 398 IAEA dengan perhitungan yang diperoleh dari proses peluruhan Co-60 . Memon melakukan variasi terhadap dua jenis pesawat Co-60 yaitu merek Theratron 780c AECL Canada dengan GWXJ80 NPIC China, hasilnya perbandingan ketepatan dosis yang diperoleh dengan perhitungan proses peluruhan Co- 60 masih dalam batas toleransi.

Pada tindakan radioterapi, penggunaan bentuk lapangan radiasi yang digunakan bisa persegi, persegi panjang atau tidak beraturan. Sidabutar dkk (2014) melakukan perbandingan dosis radiasi terhadap variasi kedalaman dan luas lapangan penyinaran (bentuk persegi dan persegi panjang) pada pesawat terapi Co-60, dengan hasil penelitian menunjukan bahwa luas lapangan penyinaran dengan bentuk persegi dan persegi panjang memiliki nilai dosis yang hampir sama, yaitu mempunyai selisih antara 0,04-1,30 Gy.

Ketika lapangan radiasi dibentuk sesuai dengan kebutuhan pasien, maka pada kolimator pesawat teleterapi memiliki komponen yang dapat digerakkan sesuai variasi luas lapangan. Sunaryati (2006), melakukan perhitungan dosis serap lapangan persegi panjang pada LINAC, dengan orientasi rahang yang membentuk sisi panjang dan sisi pendek yang berbeda. Hasil yang diperoleh menunjukkan adanya perbedaan yang cukup berarti yakni lebih besar daripada $\pm 2 \%$ antara lapangan persegi panjang $4 \mathrm{~cm} \times 8 \mathrm{~cm}$ dan $19 \mathrm{~cm} \times 6 \mathrm{~cm}$ berdasarkan perhitungan dan pengukuran.

Pesawat terapi Co-60 dengan merek Theratron Phoenix mulai dioperasikan pada tahun 2012 , selama 7 tahun pemakaian pernah mengalami satu kali masa vakum (tidak beroperasi), yaitu Juli 2017 sampai Desember 2018. Aktivitas awal dari Co-60 sekitar 396,9 TBq dan di tahun 2019 aktivitasnya berkurang menjadi 140,6 TBq, dimana mengakibatkan berkurangnya salah satu jaminan mutu dari pesawat Co-60 yaitu dosis keluaran radiasi. Berdasarkan durasi pemakaian dan berkurangnya aktivitas sumber radioaktif dari pesawat terapi Co-60 menjadi latar belakang penelitian tentang perhitungan dosis keluaran berkas radiasi berdasarkan protokol TRS 398 IAEA, lalu hasil perhitungan TPS akan dibandingkan dengan hasil pengukuran berdasarkan protokol AAPM TG 40 dengan batas toleransi $\pm 2 \%$.

Sumber radioaktif pesawat Co-60 berada pada kapsul di dalam kepala sumber (head source), dalam keadaan off kapsul sumber tidak bergerak, sedangkan saat dilakukan penyinaran kapsul sumber radioaktif akan bergerak dan memposisikan sumber barada pada lubang penyinaran. Oleh karena sumber sering mengalami pergerakan maka dilakukan pengecekan secara berkala, dengan membandingkan dosis keluaran pada perubahan nilai panjang dan lebar dengan luas lapangan yang sama, agar sesuai dengan AAPM TG 40 dimana nilai deviasi untuk luas lapangan memiliki nilai toleransi sebesar $\pm 2 \%$. 


\section{METODE PENELITIAN}

Pengukuran keluaran berkas radiasi pada pesawat terapi Co-60 dilakukan untuk mengetahui kondisi pesawat terapi Co-60 selama digunakan, agar berkas radiasi yang keluar sesuai dengan kebutuhan pasien. Pengukuran dosis dilakukan dalam medium fantom air dengan kondisi SSD $80 \mathrm{~cm}$ dan luas lapangan penyinaran yang divariasikan yaitu $10 \mathrm{~cm} \times 10 \mathrm{~cm} ; 5 \mathrm{~cm} \times 6 \mathrm{~cm} ; 6$ $\mathrm{cm} \times 5 \mathrm{~cm} ; 5,5 \mathrm{~cm} \times 5,5 \mathrm{~cm} ; 5 \mathrm{~cm} \times 8 \mathrm{~cm} ; 8 \mathrm{~cm} \times 5 \mathrm{~cm} ; 6,2 \mathrm{~cm} \times 6,2 \mathrm{~cm} ; 5 \mathrm{~cm} \times 13 \mathrm{~cm} ; 13 \mathrm{~cm}$ x $5 \mathrm{~cm} ; 7,2 \mathrm{~cm} \times 7,2 \mathrm{~cm} ; 6 \mathrm{~cm} \times 12 \mathrm{~cm} ; 12 \mathrm{~cm} \times 6 \mathrm{~cm} ; 8 \mathrm{~cm}$ x $8 \mathrm{~cm} ; 6 \mathrm{~cm}$ x $19 \mathrm{~cm} ; 19 \mathrm{~cm}$ x 6 $\mathrm{cm} ; 9,1 \mathrm{~cm} \times 9,1 \mathrm{~cm}$ dengan kedalaman $5 \mathrm{~cm}$. Langkah-langkah penelitian dapat dilihat pada Gambar 2.1.

\subsection{Persiapan Alat}

Alat dan bahan yang diperlukan selama penelitian dipasang sesuai dengan protokol TRS 398 IAEA, yaitu fantom diisi dengan air, SSD $80 \mathrm{~cm}$, ionization chamber diletakkan pada kedalaman $5 \mathrm{~cm}$. Suhu air dalam fantom, kelembaman udara dan tekanan udara dalam ruangan dicatat karena akan digunakan untuk perhitungan selanjutnya. Semua alat dalam keadaan terpasang dam belum memancarkan sinar.

\subsection{Data Kalibrasi Elektrometer dan Ionization Chamber}

Data kalibrasi elektrometer dikeluarkan oleh badan yang megkalibrasi alat tersebut, dalam hal ini elektrometer dikalibrasi oleh BATAN. Sertifikat kalibrasi elektrometer dan ionization chamber dapat dilihat pada Lampiran A.

\subsection{Perhitungan Treatment Planning System}

Pada tahap perhitungan TPS, yang dihitung adalah berapa lama waktu yang dibutuhkan fantom untuk menerima dosis radiasi dalam sekali penyinaran, sehingga setara dengan dosis radiasi dari aktivitas sumber radioaktif yang mengalami peluruhan. Perhitungan dibutuhkan karena sumber radioaktif memiliki waktu paro dimana waktu yang diperlukan sumber radioaktif sehingga jumlah inti radioaktif berkurang menjadi setengahnya dan mempengaruhi dosis radiasi yang dipancarkan.

\subsection{Penyinaran Fantom}

Penyinaran dilakukan sesuai dengan lama waktu yang dihitung dalam perhitungan TPS. Peneliti berada di dalam ruang operator yang terkoneksi dengan CCTV ruangan penyinaran selama proses penyinaran berlansung. Dosis radiasi yang dipancarkan sumber akan ditangkap oleh ionization chamber yang berada di dalam fantom air, lalu nilai dosis radiasi lansung terbaca di elektrometer yang berada di ruang operator.

\subsection{Pengukuran Faktor Koreksi}

Penentuan nilai keluaran berkas radiasi pada pesawat terapi Co-60 diperlukan beberapa faktor koreksi untuk menentukan laju dosis serap berkas radiasi di dalam air. Faktor koreksi tersebut antara lain: 


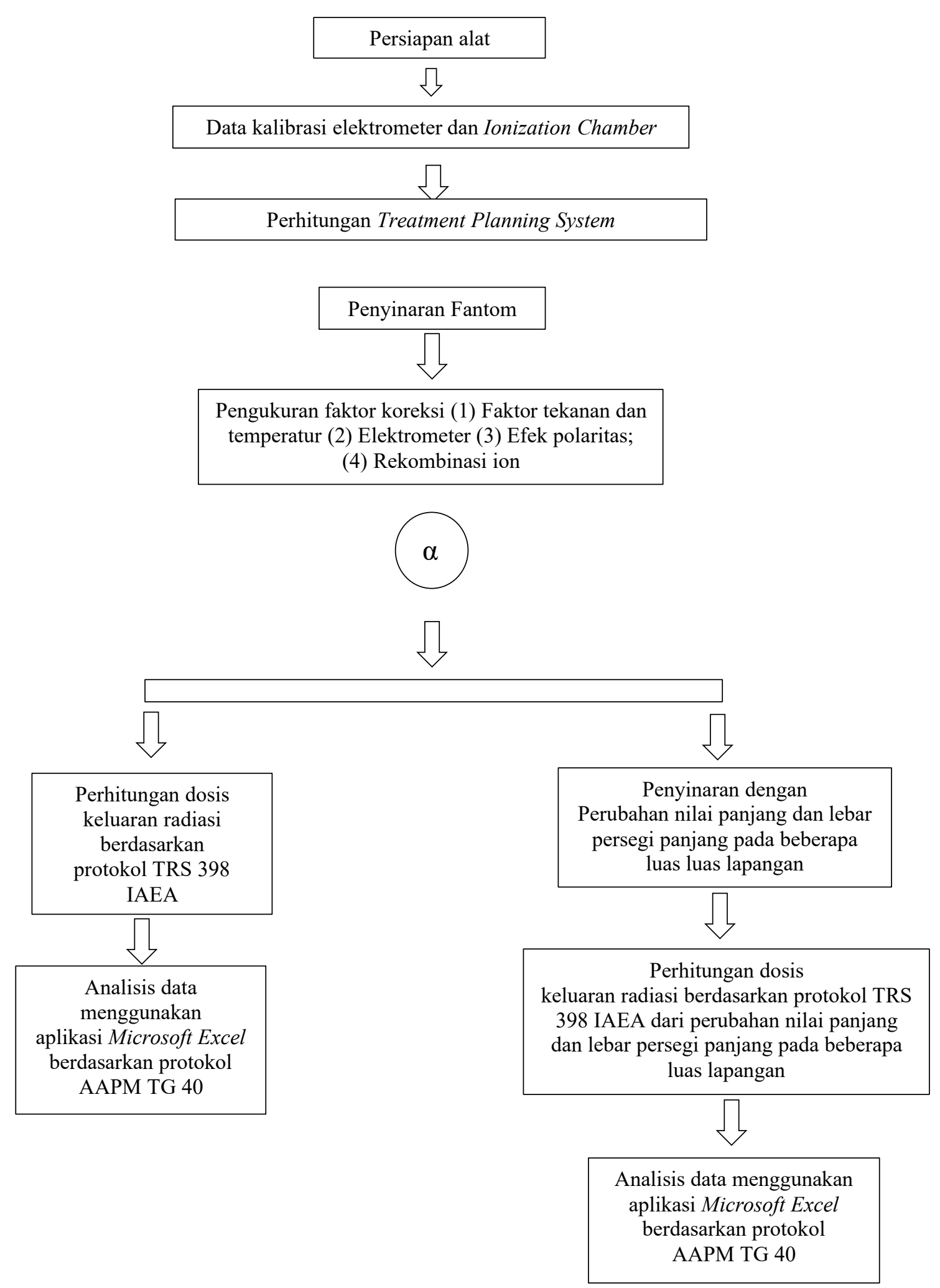

Gambar 1. Langkah - langkah penelitian 


\subsubsection{Faktor tekanan dan temperatur (kTP)}

Pengukuran faktor koreksi dilakukan dengan cara mengukur nilai tekanan udara pada saat pengukuran berlangsung dengan menggunakan barometer dan suhu rongga chamber yang berdasarkan suhu air di sekitar chamber dengan menggunakan termometer. Setelah data pengukuran tekanan dan temperatur diperoleh, nilai faktor koreksinya $\left(k_{T P}\right)$ dapat dihitung menggunakan Persamaan (1) (TRS, 2000).

$$
k_{T P}=\frac{273,15+T}{273,15+T_{0}} \frac{P_{0}}{P}
$$

\subsubsection{Elektrometer $\left(k_{\text {elec }}\right)$}

Faktor kalibrasi elektrometer bernilai 1. Hal tersebut menunjukkan ionization chamber dikalibrasi bersamaan dengan elektrometer.

\subsubsection{Efek polaritas $\left(k_{\text {pol }}\right)$}

Faktor koreksi respon detektor ionisasi terhadap efek pergantian polaritas (positif atau negatif) yang diberikan pada detektor saat penyinaran. Dalam hal ini polaritas yang diukur dengan memberikan tegangan tinggi dan tegangan rendah. Polaritas positif diperoleh saat tegangan yang diberikan bernilai positif, dan polaritas negatif diperoleh saat tegangan yang diberikan bernilai negatif. Setelah diperoleh data pengukuran, efek polaritas $\left(k_{p o l}\right)$ dapat dihitung menggunakan Persamaan (2) (TRS, 2000).

$$
k_{p o l}=\frac{\left|M_{+}\right|+\left|M_{-}\right|}{2 M}
$$

\subsubsection{Rekombinasi ion $\left(k_{s}\right)$}

Rekombinasi ion adalah proses dimana ion positif menangkap elektron bebas dan bergabung dengan elektron atau ion negatif untuk membentuk atom netral yang baru. Faktor koreksi rekombinasi ion ini ditentukan dengan mengukur tegangan yang biasa digunakan beserta tegangan referensinya. Selanjutnya dihitung menggunakan Persamaan (3) (TRS, 2000).

$$
k_{s}=\frac{\left(V_{1} / V_{2}\right)^{2}-1}{\left(V_{1} / V_{2}\right)^{2}-\left(M_{1} / M_{2}\right)}
$$

\subsection{Penyinaran dengan Perubahan Nilai Panjang dan Lebar}

Penyinaran dengan variasi luas lapangan dilakukan tanpa perhitungan TPS, karena fasilitas TPS rumah sakit belum ditingkatkan, sehingga kedalaman dan waktu penyinaran dilakukan sesuai protokol TSR 398 IAEA yaitu kedalaman $5 \mathrm{~cm}$ dan SSD $80 \mathrm{~cm}$.

\subsection{Perhitungan Dosis Keluaran Radiasi Berdasarkan Protokol TRS 398 IAEA}

Perhitungan dosis keluaran berdasarkan protokol TRS 398 IAEA menggunakan Persamaan (4) (TRS, 2000).

$$
M=M_{r} \times k_{p o l} \times k_{s} \times k_{\text {elec }} \times k_{t p}
$$


Penyinaran dilakukan sebanyak tiga kali karena dibutuhkan deviasi agar perhitungan menjadi presisi dan akurat, lalu persentase error dari masing - masing penyinaran dihitung menggunakan Persamaan (5) (TRS, 2004).

$$
\% \text { Error }=\frac{\left|D O_{T P S}-D O_{M}\right|}{D O_{M}} \times 100
$$

\subsection{Perhitungan Dosis Keluaran Radiasi dari Perubahan Nilai Panjang dan Lebar Persegi Panjang}

Perhitungan dosis keluaran radiasi dengan variasi luas lapangan menggunakan Persamaan (6) (TRS, 2000)

$$
D_{w, Q}\left(z_{\max }\right)=100 \times D_{w, Q}\left(z_{\text {ref }}\right) / P D D\left(z_{\text {ref }}\right)
$$

Variasi luas lapangan persegi panjang dengan mengubah $\mathrm{x}$ dan y serta luas lapangan persegi yang ekuivalen dengan pergantian nilai panjang dan lebar persegi panjang.

\subsection{Analisis Data Berdasarkan AAPM TG 40}

Hasil pengukuran dari penyinaran rekomendasi TRS 398 IAEA dianalisis dengan membandingkan persentase error nilai dosis keluaran perhitungan TPS dengan dosis keluaran pada saat penyinaran melalui Persamaan (5). hasil perbandingan dibandingkan dengan quality assurance Co-60 dari protokol AAPM TG 40. Begitu juga dengan hasil pengukuran dari perubahan nilai panjang dan lebar persegi panjang pada beberapa luas lapangan, nilai persentase perbandingan atau error dapat dihitung menggunakan Persamaan (7) (TRS, 2000)

$$
D_{w, Q}\left(z_{\text {ref }}\right)=M \times N_{D, w}
$$

dan (6) dibandingkan dengan quality assurance Co-60 dari protokol AAPM TG 40.

\section{HASIL DAN PEMBAHASAN}

\subsection{Pengukuran Jumlah Muatan Berkas Foton}

Data pengukuran jumlah muatan rata-rata untuk menentukan nilai faktor koreksi efek polaritas dan rekombinasi ion pada berkas foton dapat dilihat pada Tabel 1 dengan variasi

\begin{tabular}{|c|c|c|c|c|c|}
\hline Energi $(\mathrm{MeV})$ & V (Volt) & $\mathrm{P}$ (mBar) & $\mathrm{T}\left({ }^{\circ} \mathrm{C}\right)$ & RH (\%) & $\mathrm{Mr}(\mathrm{nC} / \mathrm{min})$ \\
\hline \multirow{3}{*}{1,25} & +300 & \multirow{3}{*}{1008} & \multirow{3}{*}{20} & \multirow{3}{*}{56,9} & 15,17 \\
\hline & -300 & & & & 15,13 \\
\hline & +75 & & & & 15,12 \\
\hline
\end{tabular}
tegangan $+300 \mathrm{~V}$, dan-300 V .

Tabel 1 Data pengukuran jumlah muatan berkas foton

Tabel 1 merupakan data pengukuran jumlah muatan berkas foton pada saat penyinaran, data tersebut adalah energi, tegangan, tekanan, suhu, kelembaban dan hasil bacaan elektrometer. Energi yang dipancarkan oleh pesawat teleterapi Co-60 rata-rata sebesar 1,25 MeV, energi ini merupakan energi dari aktivitas sumber radiasi Co-60 yang meluruh. Tegangan sebesar +300 $\mathrm{V}$ dan $-300 \mathrm{~V}$, tegangan divariasikan karena diperlukan untuk menentukan faktor koreksi polaritas dimana nilainya sama namun berlawanan (positif dan negatif). Tegangan $+75 \mathrm{~V}$ diperlukan untuk menghitung faktor koreksi rekombinasi ion yang menghasilkan nilai $\mathrm{M}$, dimana tegangan yang diperlukan untuk mendapatkan nilai $\mathrm{M}$ adalah dengan penyinaran pada 
tegangan seperempat dari nilai tegangan awal. Tekanan, suhu dan kelembaban merupakan data yang diambil pada saat penyinaran berlansung, diambil pada saat penyinaran karena tekanan, suhu dan kelembaban cenderung berubah-ubah pada setiap keadaan, data ini juga diperlukan untuk menghitung faktor koreksi tekanan, suhu dan kelembaban $\left(k_{t p}\right)$ terhadap keadaan referensi, keadaan referensi terdapat pada sertifikat kalibrasi elektrometer. Mr merupakan nilai yang ditampilkan oleh elektrometer yang berada di ruang operator, nilai didapatkan dari hasil tangkapan dosimeter ionization chamber yang menerima pancaran radiasi dari pesawat teleterapi Co-60. Dosimeter ionization chamber berada di dalam fantom air.

\subsection{Perhitungan Faktor Koreksi Berkas Foton}

Nilai perhitungan faktor koreksi pada berkas foton pesawat terapi Co-60 yang diperoleh dapat dilihat pada Tabel 2. Nilai perhitungan faktor koreksi digunakan untuk menentukan keluaran berkas foton pada kedalaman referensi ekuivalen $\left(\mathrm{Z}_{\mathrm{ref}}\right) 5 \mathrm{~g} / \mathrm{cm}^{2}$.

Tabel 2. Nilai faktor-faktor koreksi keluaran berkas foton

\begin{tabular}{ccc}
\hline No & Faktor Koreksi & Hasil \\
\hline 1 & $k_{t p}$ & 1,005 \\
\hline 2 & $k_{\text {pol }}$ & 0,999 \\
\hline 3 & $k_{s}$ & 1,000 \\
\hline 4 & $k_{\text {elec }}$ & 1,000 \\
\hline 5 & PDDz & 78,80 \\
\hline
\end{tabular}

Semua nilai faktor-faktor koreksi keluaran berkas foton bernilai \pm 1 . Hal ini berarti nilai faktor koreksi yang didapatkan telah sesuai dengan dengan standar yang ditetapkan TRS 398 IAEA dimana masing-masing nilai faktor koreksi mendekati 1 , artinya nilainya tidak jauh berbeda dengan keadaan standar. Selanjutnya, nilai faktor-faktor koreksi yang telah diperoleh digunakan sebagai parameter dalam perhitungan keluaran berkas radiasi foton untuk variasi luas lapangan.

\subsection{Perhitungan Keluaran Berkas Foton}

Hasil perhitungan keluaran berkas foton dapat dilihat pada Tabel 3.

Tabel 3. Perhitungan keluaran berkas foton

\begin{tabular}{cccc}
\hline $\begin{array}{c}\text { Penyinaran } \\
\text { Ke- }\end{array}$ & $\begin{array}{c}\text { Dosis Keluaran pada } \\
\text { Saat Penyinaran } \\
(\mathrm{mGy} / \mathrm{min})\end{array}$ & $\begin{array}{c}\text { Dosis Keluaran } \\
\text { Perhitungan TPS } \\
(\mathrm{mGy} / \mathrm{min})\end{array}$ & \%Error \\
\hline 1 & 987 & 986,5 & 0,051 \\
\hline 2 & 987 & 986,5 & 0,051 \\
\hline 3 & 987 & 986,5 & 0,051 \\
\hline 4 & 987 & 986,5 & 0,051 \\
\hline 5 & 987 & 986,5 & 0,051 \\
\hline
\end{tabular}

Berdasarkan Tabel 3. dosis keluaran berkas foton yang diperoleh dengan lima kali penyinaran sebesar $987 \mathrm{mGy} / \mathrm{min}$, nilai tidak banyak mengalami perubahan karna waktu penyinaran sama yaitu 60 detik, dan jeda antara penyinaran satu dengan yang lain sekitar 20 detik. Dosis keluaran hasil perhitungan TPS adalah 986,5 $\mathrm{mGy} / \mathrm{min}$, karena variabel perhitungan dosis keluaran tidak berubah maka nilai ini digunakan untuk dibandingkan ke 
seluruh nilai dosis keluaran pada saat penyinaran. Perbandingan nilai dosis keluaran pada saat penyinaran dengan nilai dosis hasil perhitungan TPS memiliki penyimpangan sebesar $0,051 \%$, penyimpangan ini masih berada dalam batas toleransi TRS No. 398 IAEA dan AAPM 40 yaitu $2 \%$. Hasil keluaran berkas foton yang telah diperoleh menunjukkan hasil penelitian ini tidak jauh berbeda dengan hasil penelitian Baba (2013) dan Memon (2017).

\subsection{Pengukuran Dosis Keluaran Berkas Foton dari Perubahan Nilai Panjang dan Lebar Persegi Panjang pada Beberapa Luas Lapangan}

Pengukuran dilakukan untuk mengetahui dosis keluaran yang diterima fantom dari setiap perubahan nilai panjang dan lebar persegi panjang yang dapat dilihat pada Tabel 4.

Tabel 4. Hasil pengukuran dosis keluaran berkas foton dari perubahan nilai panjang dan lebar persegi panjang pada beberapa luas lapangan

\begin{tabular}{|c|c|c|c|c|c|}
\hline $\begin{array}{l}\text { Luas Lapangan } \\
(\mathrm{cm} \times \mathrm{cm})\end{array}$ & $\operatorname{Mr}(\mathrm{nC} / \mathrm{min})$ & $\begin{array}{l}\text { Faktor } \\
\text { Pengali }\end{array}$ & $\begin{array}{l}\mathrm{D}_{\mathrm{w}, \mathrm{Q}} \\
\left(\mathrm{Z}_{\mathrm{ref}}\right)\end{array}$ & $\begin{array}{c}\text { PDD } \\
(\%)\end{array}$ & $\begin{array}{c}\mathrm{D}_{\mathrm{w}, \mathrm{Q}} \\
\left(\mathrm{Z}_{\mathrm{maks}}\right)\end{array}$ \\
\hline $5 \times 6$ & 13,98 & \multirow{3}{*}{51,00} & 713 & \multirow{3}{*}{75,70} & 942 \\
\hline $6 \times 5$ & 13,92 & & 710 & & 938 \\
\hline $5,5 \times 5,5$ & 14,00 & & 714 & & 943 \\
\hline $5 \times 8$ & 14,24 & \multirow{3}{*}{51,00} & 726 & \multirow{3}{*}{76,30} & 952 \\
\hline $8 \times 5$ & 14,23 & & 726 & & 951 \\
\hline $6,2 \times 6,2$ & 14,27 & & 728 & & 954 \\
\hline $5 \times 13$ & 14,63 & \multirow{3}{*}{51,00} & 746 & \multirow{3}{*}{77,10} & 968 \\
\hline $13 \times 5$ & 14,60 & & 745 & & 966 \\
\hline $7,2 \times 7,2$ & 14,59 & & 744 & & 965 \\
\hline $6 \times 12$ & 14,83 & \multirow{3}{*}{51,00} & 756 & \multirow{3}{*}{77,80} & 972 \\
\hline $12 \times 6$ & 14,79 & & 754 & & 970 \\
\hline $8 \times 8$ & 14,80 & & 755 & & 970 \\
\hline $6 \times 19$ & 15,18 & \multirow{3}{*}{51,00} & 774 & \multirow{3}{*}{78,30} & 989 \\
\hline $19 \times 6$ & 15,09 & & 770 & & 983 \\
\hline $9,1 \times 9,1$ & 15,08 & & 769 & & 982 \\
\hline
\end{tabular}

Berdasarkan Tabel 4 ada beberapa data yang diinputkan kedalam perhitungan pengukuran dosis keluaran berkas foton. Pada Persamaan (7) yang mempengaruhi nilai dosis serap pada kedalaman $Z_{\text {ref }}$ adalah hasil pembacaan dosimeter ionization chamber yang telah dikoreksi secara total oleh faktor koreksi, serta faktor kalibrasi yang tertera pada sertifikat kalibrasi. Namun pada penelitian ini terdapat perubahan nilai dosis serap ketika dibuat variasi nilai panjang dan lebar dari persegi panjang tetapi masih dalam nilai luas yang sama. Nilai Mr pada luas lapangan yang sama $\left(30 \mathrm{~cm}^{2}\right)$ namun nilai panjang dan lebar persegi panjang divariasikan, nilainya tetap berubah, ini menunjukkan adanya pengaruh perubahan nilai panjang dan lebar luas lapangan penyinaran, karena ketika melakukan perubahan tersebut pesawat Co-60 dalam keadaan off untuk menyesuaikan bentuk kolimator dengan lapangan yang diinginkan, sehingga peneliti tidak terpapar radiasi dari pesawat. Nilai Mr didapatkan dari hasil bacaan elektrometer yang terhubung dengan dosimeter ionization chamber di ruang penyinaran di dalam fantom, nilai Mr juga berubah sering dengan perubahan nilai luas lapangan, makin luas lapangan makin besar nilai Mr. Faktor pengali merupakan nilai perkalian total dari faktor koreksi dengan faktor kalibrasi. $D_{W, Q}\left(\mathrm{Z}_{\mathrm{ref}}\right)$ adalah nilai dosis serap berkas foton dari hasil perkalian nilai Mr dengan 
faktor pengali. Selanjutnya nilai dosis keluaran pada kedalaman maksimum merupakan niali $D$ $W, Q$ (Zref) dikalikan dengan nilai PDD pada masing-masing luas lapangan.

\subsection{Perbandingan Dosis Keluaran Berkas Foton dari Perubahan Nilai Panjang dan Lebar Persegi Panjang pada Beberapa Luas Lapangan}

Perhitungan dosis keluaran berkas foton dapat dilihat pada Tabel 4, selanjutnya membandingkan nilai dosis keluaran berkas foton dari perubahan nilai panjang dan lebar persegi panjang tersebut agar diketahui nilai persentase error atau deviasi pada setiap perubahan nilai panjang dan lebar pada luas lapangan persegi panjang, dimana persentase error atau deviasi tersebut mengacu pada protokol AAPM TG 40. Hasil perbandingan dosis keluaran berkas foton dari perubahan nilai $\mathrm{x}$ dan y persegi panjang dapat dilihat pada Tabel 5.

Tabel 5. Hasil perbandingan dosis keluaran berkas foton dari perubahan nilai panjang dan lebar persegi panjang pada beberapa luas lapangan

\begin{tabular}{|c|c|c|c|c|c|c|c|}
\hline $\begin{array}{c}\text { Luas } \\
\text { Lapangan } \\
(\mathrm{cm} \times \mathrm{cm})\end{array}$ & $\begin{array}{c}\text { Panjang } \\
(\mathrm{cm})\end{array}$ & $\begin{array}{c}\text { Lebar } \\
(\mathrm{cm})\end{array}$ & $\begin{array}{c}\text { Dosis } \\
\text { Keluaran } \\
\text { (cGy/min) }\end{array}$ & $\alpha(\%)$ & $\begin{array}{c}\text { Luas } \\
\text { Lapangan } \\
\text { Ekuivalen } \\
(\mathrm{cm} \mathrm{x} \mathrm{cm)}\end{array}$ & $\begin{array}{c}\text { Dosis } \\
\text { Keluaran } \\
\text { (cGy/min) }\end{array}$ & $\beta(\%)$ \\
\hline \multirow{2}{*}{$5 \times 6$} & 5 & 6 & 942 & & \multirow{2}{*}{$5,5 \times 5,5$} & 943 & 0,106 \\
\hline & 6 & 5 & 938 & 0,426 & & 943 & 0,530 \\
\hline \multirow{2}{*}{$5 \times 8$} & 5 & 8 & 952 & & \multirow{2}{*}{$6,2 \times 6,2$} & 954 & 0,210 \\
\hline & 8 & 5 & 950 & 0,211 & & 954 & 0,419 \\
\hline \multirow{2}{*}{$5 \times 13$} & 5 & 13 & 967 & & \multirow{2}{*}{$7,2 \times 7,2$} & 965 & 0,207 \\
\hline & 13 & 5 & 966 & 0,104 & & 965 & 0,104 \\
\hline \multirow{2}{*}{$6 \times 12$} & 6 & 12 & 972 & & \multirow{2}{*}{$8 \times 8$} & 954 & 0,206 \\
\hline & 12 & 6 & 970 & 0,206 & & 954 & 0,000 \\
\hline \multirow{2}{*}{$6 \times 19$} & 6 & 19 & 989 & & \multirow{2}{*}{$9,1 \times 9,1$} & 982 & 0,713 \\
\hline & 19 & 6 & 983 & 0,610 & & 982 & 0,102 \\
\hline
\end{tabular}

Berdasarkan Tabel 5 nilai error atau deviasi keluaran berkas foton yang diperoleh masingmasing perubahan nilai panjang dan lebar pada beberapa luas lapangan tidak melebihi $2 \%$. Pada luas lapangan $5 \mathrm{~cm}$ x $6 \mathrm{~cm}\left(30 \mathrm{~cm}^{2}\right)$ nilai dosis keluaran sebesar $942 \mathrm{cGy} / \mathrm{min}$. Selanjutnya nilai dosis keluaran dari perubahan nilai panjang dan lebar dengan luas lapangannya sama $\left(30 \mathrm{~cm}^{2}\right)$ yaitu untuk $6 \mathrm{~cm}$ x $5 \mathrm{~cm}$ sebesar $938 \mathrm{cGy} / \mathrm{min}$, nilai error-nya sebesar $0,426 \%$, dan untuk 5,5 $\mathrm{cm}$ x 5,5 cm sebesar $943 \mathrm{cGy} / \mathrm{min}$, nilai error terhadap $5 \mathrm{~cm}$ x $6 \mathrm{~cm}$ sebesar 0,106\%, sedangkan terhadap $6 \mathrm{~cm} \times 5 \mathrm{~cm}$ sebesar $0,530 \%$. Berdasarkan data tersebut meskipun perubahan nilai terjadi karena perubahan nilai panjang dan lebar namun perubahannya masih dibawah batas toleransi pada prtokol AAPM TG 40 yaitu sebesar $2 \%$.

Dilihat dari empat luas lapangan lainnya nilai error yang diperoleh dari perubahan nilai panjang dan lebar persegi panjang pada luas lapangan yang sama memiliki error yang tidak lebih $2 \%$. Nilai error terbesar terdapat pada luas lapangan $6 \mathrm{~cm} \times 19 \mathrm{~cm}$ terhadap perubahan luas lapangan ekuivalen $9,1 \mathrm{~cm}$ x 9,1 cm sebesar $0,713 \%$ hal ini terjadi karena mekanisme on ke off ataupun sebaliknya sering dilakukan mengingat luas lapangan 9,1 cm x 9,1 cm adalah penyinaran terakhir membuat pergerakan piston menjadi terganggu, sedangkan nilai error terkecil terdapat pada luas lapangan $6 \mathrm{~cm} \times 12 \mathrm{~cm}$ dimana nilai error $0,00 \%$ dari nilai dosis keluaran berkas $12 \mathrm{~cm} \times 6 \mathrm{~cm}$ terhadap $8 \mathrm{~cm}$ x $8 \mathrm{~cm}$. Nilai ini bisa terjadi mengingat dalam perhitungan dosis keluaran tidak mempertimbangkan luas lapangan. 


\section{KESIMPULAN}

Berdasarkan penelitian yang telah dilakukan untuk analisis perbandingan nilai dosis keluaran berkas radiasi pada perubahan nilai panjang dan lebar dengan luas lapangan yang sama dapat disimpulkan bahwa :

1. Nilai dosis keluaran berkas radiasi pesawat Co-60 Rumah Sakit Dr. M.Djamil Padang dalam keadaan optimal. Nilai error antara dosis keluaran pada saat penyinaran dengan nilai dosis keluaran berkas perhitungan TPS didapatkan sebesar $0.051 \%$ dimana masih berada dibawah batas toleransi AAPM TG 40 yaitu sebesar 2\%.

2. Mekanisme on ke off pesawat teleterapi Co-60 Rumah Sakit Dr. M.Djamil Padang dalam keadaan optimal yang dapat dilihat pada perbandingan nilai dosis keluaran berkas radiasi pada setiap perubahan nilai panjang dan lebar persegi panjang dengan luas lapangan yang sama tidak melebihi batas toleransi protokol AAPM TG 40 yaitu sebesar $2 \%$.

\section{SARAN}

Berdasarkan penelitian yang telah dilakukakan, disarankan untuk melakukan pengecekkan oleh fisikawan medis, maupun elektro medis terhadap komponen lainnya dari pesawat teleterapi Co-60 seperti kolimator, gantri dll, dan juga melakukan pengukuran dosis keluaran berkas dengan teknik penyinaran yang lain maupun menambah variasi luas lapangan agar dosis yang diterima pasien tepat sesuai kebutuhan.

\section{DAFTAR PUSTAKA}

Baba, M.H, Haq, M.M.U, dan Khan, A.A, 2013, Dosimetric Consistency of Co-60 Teletherapy Unit a Ten Years Study, Vol 7, No. 1, International Journal of Health Sciences, Qassim University, hal 13-18.

Memon, S.A, Laghari, N.A, Mangi, F.H, Jafri, M.A, Raza, M, dan Abbasi, M.A, 2017, Dosimetric Conformity of Cobalt-60 Beams, International Journal of Science and Engineering Investigations, Vol 6, No. 65, Karakoram International University, hal 90 $-93$.

Sidabutar, D.H, dan Setiawan, E., 2014, Perbandingan Dosis Terhadap Variasi Kedalaman dan Luas Lapangan Penyinaran (Bentuk Persegi dan Persegi Panjang) Pada Pesawat Terapi C0-60, Youngster Physics Journal, Vol.3, No.4, Universitas Diponegoro, hal 295-302.

Sunaryati, S.I, 2006, Penentuan Dosis Serap Lapangan Radiasi Persegi Panjang Berkas Photon 10 MV dengan Pengukuran dan Perhitungan, Prosiding Seminar Keselamatan Nuklir, Jakarta.

TRS 398, 2000, Absorbed Dose Determination in External Beam Radiotherapy, IAEA, Austria

TRS 430, 2004, Commissioning and Quality Assurance of Computerized Planning System for Radiation Treatment of Cancer, IAEA, Austria. 